\title{
Innovative Ultrasonic Techniques for Inspection and Monitoring of Large Concrete Structures
}

\author{
H. Wiggenhauser ${ }^{1}$, E. Niederleithinger ${ }^{1}$
}

${ }^{1}$ BAM Federal Institute for Materials Research and Testing, Berlin, Germany

\begin{abstract}
Ultrasonic echo and transmission techniques are used in civil engineering on a regular basis. New sensors and data processing techniques have lead to many new applications in the structural investigation as well as quality control. But concrete structures in the nuclear sector have special features and parameters, which pose problems for the methods and instrumentation currently available, e.g. extreme thickness, dense reinforcement, steel liners or special materials. Several innovative ultrasonic techniques have been developed to deal with these issues at least partly in lab experiments and pilot studies. Modern imaging techniques as multi-offset SAFT have been used e. g. to map delaminations. Thick concrete walls have successfully been inspected, partly through a steel liner. Embedded ultrasonic sensors have been designed which will be used in monitoring networks of large concrete structures above and below ground. In addition, sensitive mathematical methods as coda wave interferometry have been successfully evaluated to detect subtle changes in material properties. Examples of measurements and data evaluation are presented.
\end{abstract}

\section{Introduction}

Ultrasonic echo and transmission techniques are used in civil engineering on a regular basis. New sensors and data processing techniques have lead to many new applications in the structural investigation as well as quality control. The state of the art is described e.g. in [1,2]. But concrete structures in the nuclear sector have special features and parameters, which pose problems for the methods and instrumentation currently available, e.g. extreme thickness, dense reinforcement, steel liners or special materials. Recent advances in instrumentation as well as data processing will help to deal with these issues.

Until about 10 years ago the application of ultrasonics to concrete inspection was limited, as only quite large, heavy transducers were available, which also required a coupling agent. Meanwhile lightweight point contact transducers for compressional and shear waves have been developed, which can be coupled to a surface by light pressure without agents. These transducers have been integrated into commercial products and are widely used for various applications. In most cases several electronically coupled transducers (e. g. 12 for transmission and 12 for receiving signals), all in one casing, are used. This fixed offset configuration is moved manually over the surface. Two problems arise by this technique: a fixed aperture which limits the detectability of certain structures 
and the time, precision and work force needed to acquire about 2500 measurements $/ \mathrm{m}^{2}$ required for appropriate results.

Data processing is currently mainly done by Synthetic Aperture Focusing Techniques (SAFT), which are used to perform subsurface image reconstruction from ultrasonic echo data. Limitations of the standard techniques are presently limited visibility of deep or hidden structures as well as reflector characterization (e. g. void or steel) or detection of subtle temporal changes.

\section{Innovative ultrasonic instrumentation and data processing}

\subsection{Automated scanning systems}

Since about 15 years several type of automated scanning systems have been developed at Federal Institute for Materials Research and Testing (BAM) to allow high precision positioning of ultrasonic sensors to horizontal or vertical surfaces. They allow the acquisition of dense grids (up to 10000 points $/ \mathrm{m}^{2}$ ) with an accuracy of a few millimeters. Repeatability is far better than in manual applications. Coupling pressure is generated by pneumatic cylinders. The scanners are mounted on the surface by suction pods, (Fig. 1 (a)) and can move the sensors on an area between 0.5 and $2 \mathrm{~m}^{2}$. Recently a near-commercial version (OSSCAR - building scanner) has been developed. Custom versions for special geometries as well as prototypes for autonomous wheel based robots (BETOSCAN - automated driven scanner system, Fig. 1 (b)) and climbing versions of our scanners are available as well.

All scanning systems developed at BAM can also be used for a large variety of non-destructive testing (NDT) methods as ground penetrating radar (GPR), impact echo, moisture sensors, half cell potential and others.

(a)

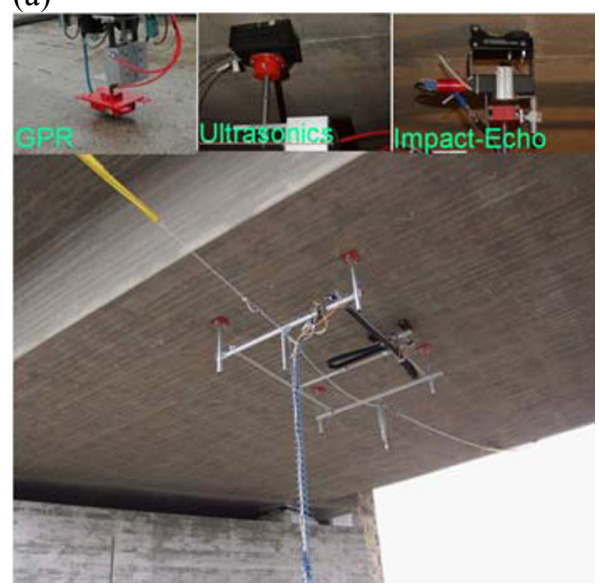

(b)

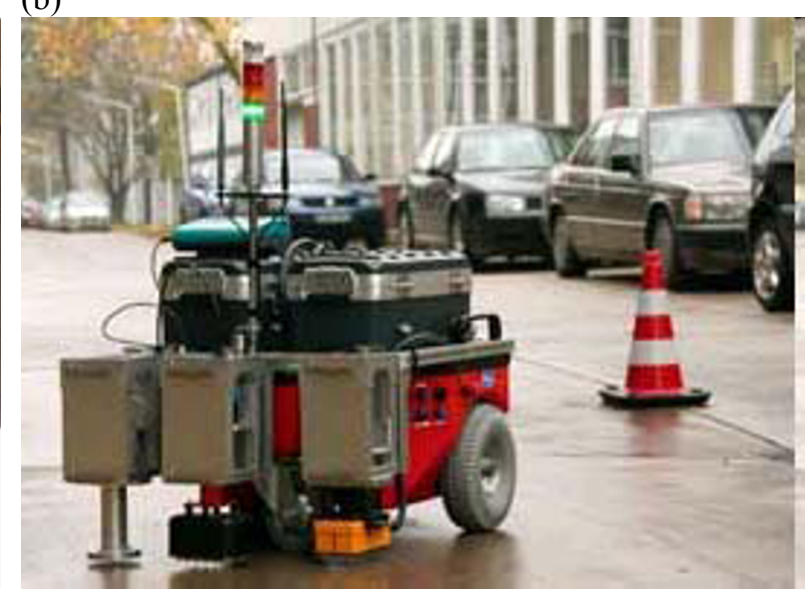

Fig. 1. Automated NDT scanning systems developed at BAM: Suction pod based frame system below a bridge deck (a) and wheel based autonomous robot BETOSCAN (b).

\subsection{Multi-Offset Array}

Recently developed multi-offset arrays of ultrasonic transducers, which are now commercially available, facilitate not only the deployment of many sensors to the surface at one time but also the application of advanced data processing schemes. Currently, the system consists of ten rows of four transducers. The transducers of each row are connected and work together to avoid noisy results, e. g. if one sensor experiences difficult coupling conditions at the concrete surface. Each row can 
work as transmitter or receiver. All combinations (Fig. 2 (a)) are switched electronically by the system software. All data are processed by the system using the established SAFT technique. The imaging result is displayed almost instantaneously on the screen (Fig. 2 (b)). This allows on-site interpretation and corrections in the measurement setup, if required. Additional data processing has to be done in the office to merge and interpret all data.

Depth of investigation is currently limited to about $2 \mathrm{~m}$. Larger arrays to allow the investigation of very thick structures are under development.
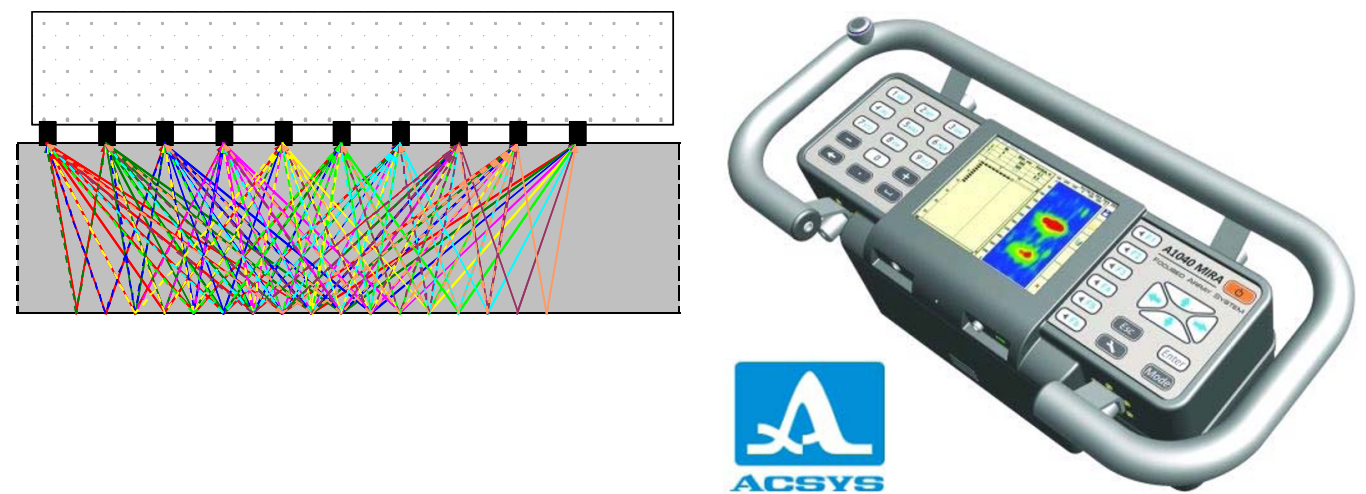

Fig. 2. a) Principle of a multi-offset linear ultrasonic array [1], b) Acsys Mira.
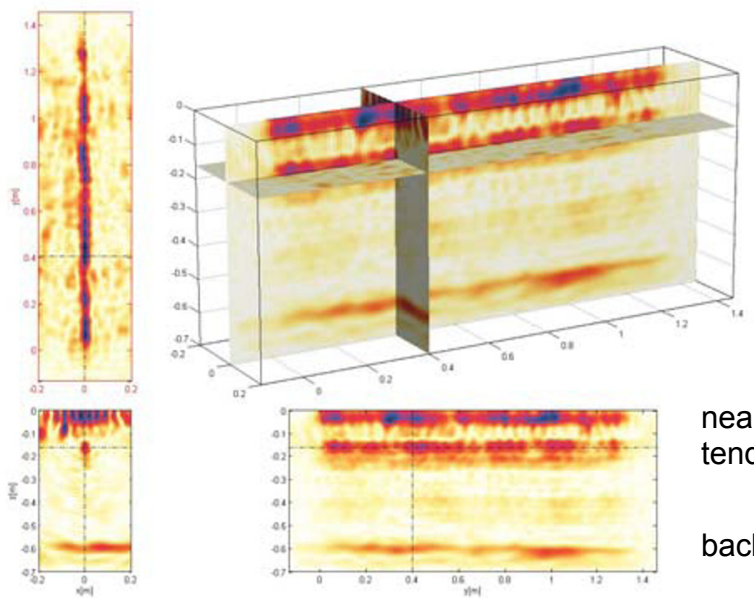

near surface effects tendon duct

backwall

Fig. 3: Sections (vertical and horizontal) through ultrasonic echo data volume acquired by a multi-offset array processed by SAFT to map a tendon duct [1].

\subsection{Enhanced Imaging}

Conventional ultrasonic imaging techniques as SAFT have some shortcomings: they are not able to distinguish between reflector types (e. g. between concrete/air, concrete/steel) and are not able to image vertical or hidden surfaces. Recently an improvement of SAFT techniques has been published [3]. Phase evaluation is used to characterize reflectors. This technique uses the fact that positive impedance contrasts (as at concrete/steel interfaces) generate a $180^{\circ}$ phase shift compared to negative impedance contrasts (as at concrete/air interfaces). Fig. 4 pictures the result of a verification 
experiment. Phase evaluation (Fig. 4 (e)) shows clearly different signatures at grouted and nongrouted sections of a tendon duct.

Further improvement is expected by the use of sophisticated imaging methods adopted from seismic oil exploration. Fig. 5 shows a synthetic example of the application of a technique called reverse time migration (RTM), which allows the imaging of vertical surfaces and the backside of tendon ducts. Until now the method lacks of a high demand on computing power and adopted measurement devices.

a)
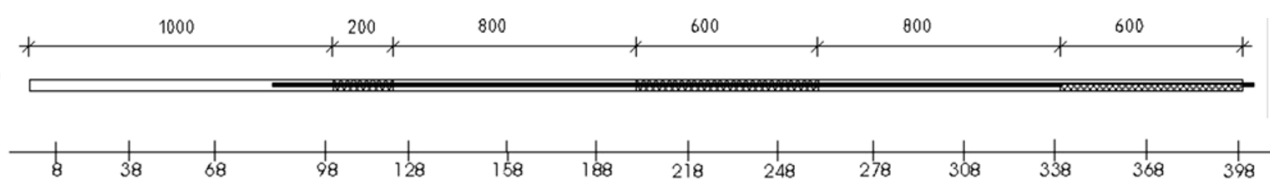

b)

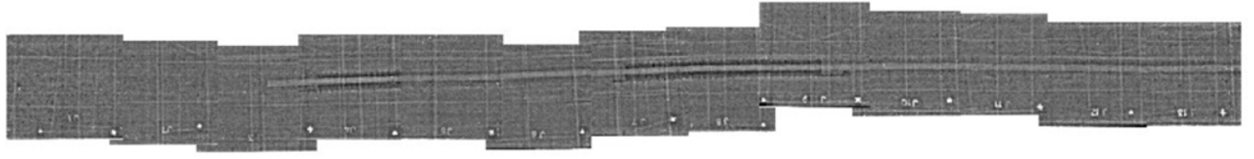

c)

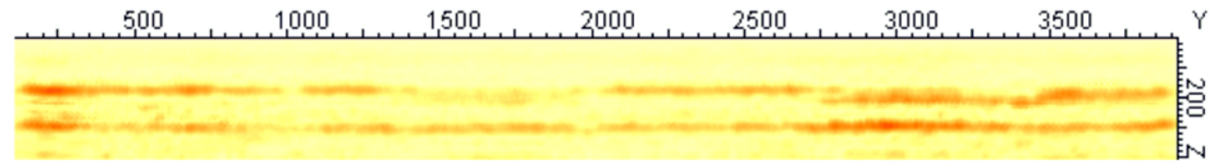

d)
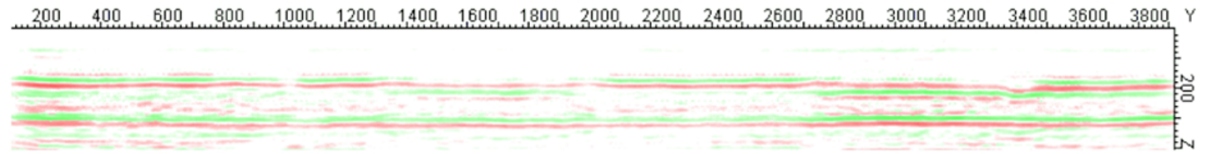

e)

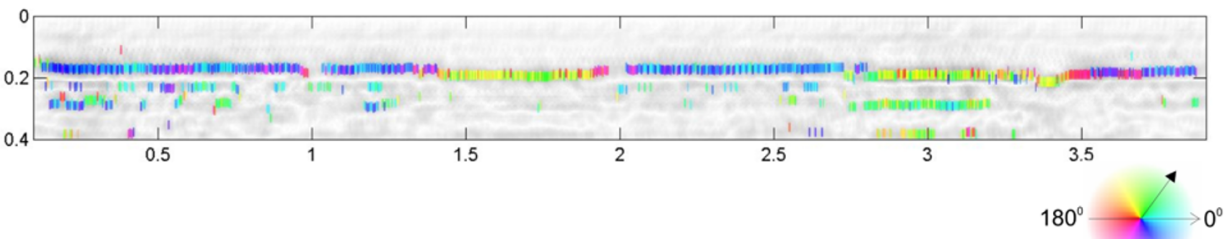

Fig. 4. Ultrasonic SAFT imaging results for partially grouted tendon duct in a test slab. (a) Sketch of the specimen with desired grouting faults, (b) Verification of grouting faults with $\gamma$-radiography, (c) Result of ultrasonic scanning (3D-SAFT), $55 \mathrm{kHz}$ shear waves, (d) Pulse shape representation of the same area, (e) Phase values of reflecting pulses around the maximum of each reflector calculated from FT-SAFT [4].

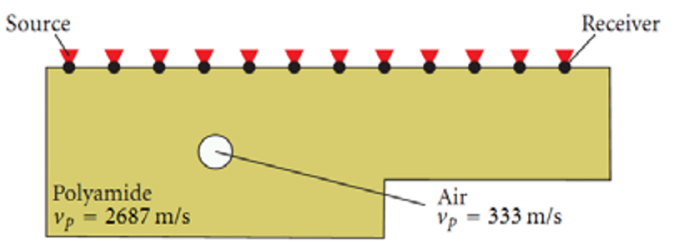

(a)

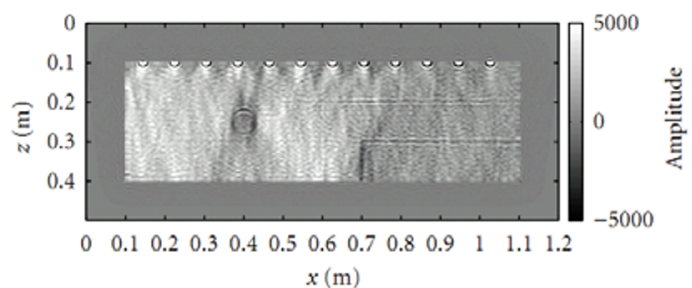

(b)

Fig. 5. a) Synthetic model with cylindrical air inclusion and varying thickness. b) RTM imaging of a) from ultrasonic multi-offset surface data without knowledge of structure [5]. 


\subsection{Embedded ultrasonic sensors}

Upcoming monitoring applications have generated the demand for a new generation of embedded ultrasonic sensors. Permanently installed US instrumentation is so far mainly used for following the hardening of concrete in new construction. However, some of these installations have survived for several decades and are still operational. New data processing techniques as Coda Wave Interferometry (section 3.3) require transceivers which do not change in their properties over time, neither regarding the sensor itself or the coupling to the concrete.

A recently developed prototype was installed in several lab specimen, some of them subjected to temperature changes (section 3.3) and/or moisture. Others were placed in a large concrete slab on an open air test site one and a half year ago. All sensors have survived and are still operational without significant changes in their properties. This development will support the design of large scale monitoring systems for structures as foundations, bridges or power plants.

(a)

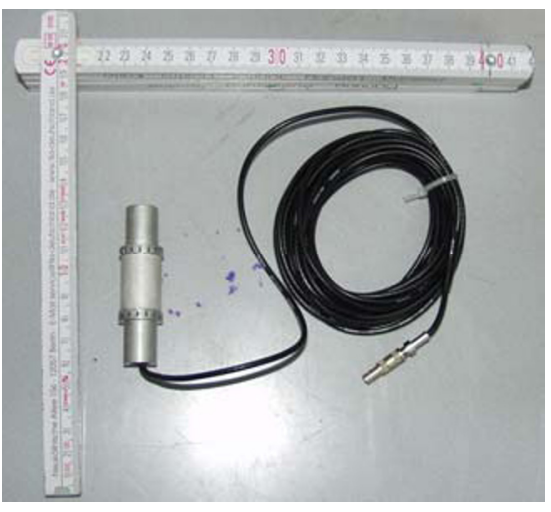

(b)

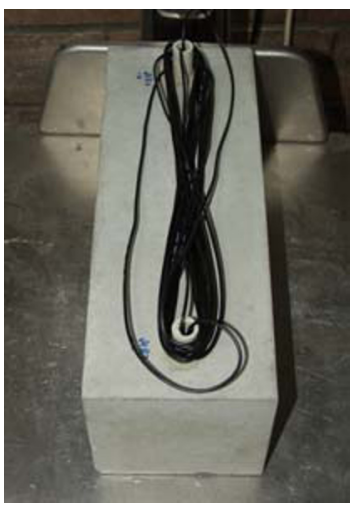

Fig. 6. Prototype of embedded ultrasonic sensor (a), embedded in test specimen (b).

\section{Application examples}

\subsection{Imaging the structure of thick concrete elements}

Until the emergence of point contact transducers and automated scanning systems the detailed investigation of large concrete structures by ultrasonics was almost impossible. In the frame of a European research project on the re-use of foundations we have tested these new developments on a slab at our large scale test site at Horstwalde, Germany. We have been able to map the geometry up to a thickness of $1.2 \mathrm{~m}$ (Fig. 7). 


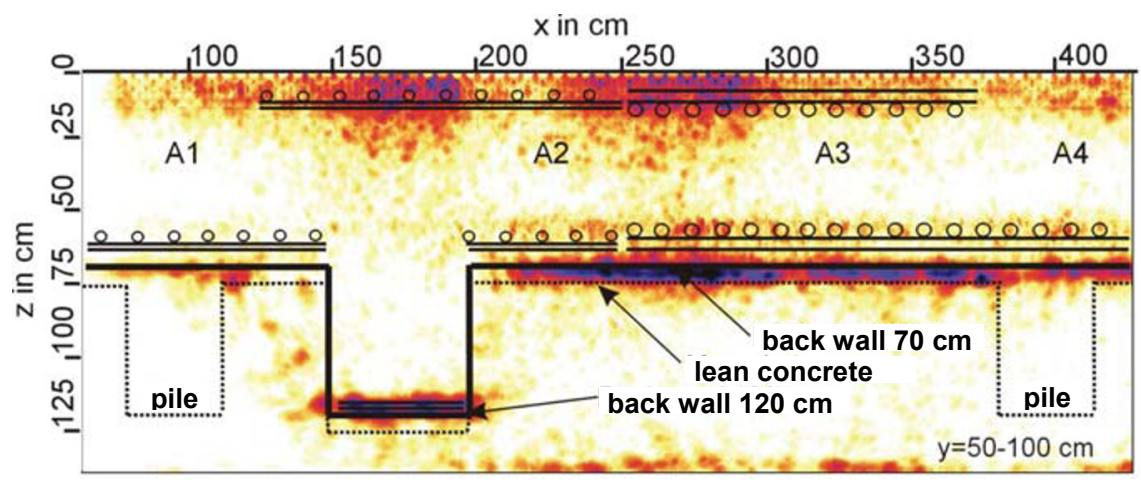

Fig. 7. B-Scan (vertical section through test slab at the BAM-TTS Horstwalde test site [6].

\subsection{Imaging the structure of concrete elements behind a steel liner}

One of the main problems in ultrasonic investigations of concrete safety containments is access to the concrete surface. The inner side of most of these structures is covered by a steel liner. As certain issues to be checked by ultrasonics relate to relative small objects or voids directly behind the liner (thus too far away from the outer, uncovered surface) it would desirable to "see" through the liner. The impedance contrast between steel and concrete resulted in the reflection of a large part of the ultrasonic energy. However, some promising experiments have been carried out, but are not yet published.

Another design includes a steel liner inside the concrete structure. Experiments on a test specimen (30 cm thickness, steel sheet in the center) have shown the possibility for detection of delaminations in front of and behind the sheet (Fig. 8).

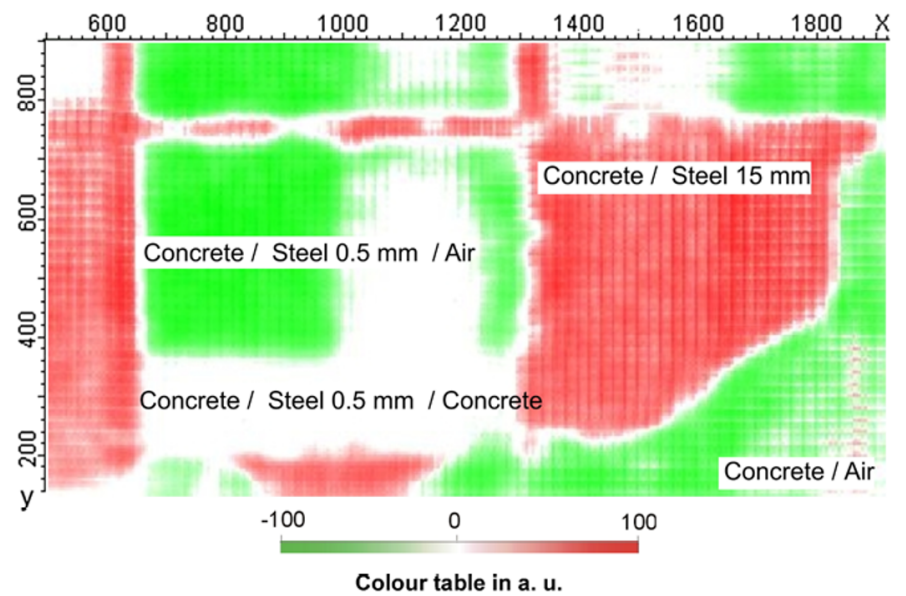

Fig. 8. Phase evaluation of ultrasonic reflections of a test slab with embedded steel liners, partially debonded [4]. 


\subsection{Monitoring subtle changes in concrete}

Concrete elements which are under cyclic loading, affected by singular events (fire, impact) or degradation (Alkali silica reaction ASR, freeze-thaw) may loose their integrity or load capacity. For safety reasons but also to perform an effective and efficient life cycle management an early detection even of subtle changes is desired. The changes in properties or internal cracking are in many cases not visible at the surface (especially behind lining systems). Conventional embedded sensors (stress, strain, temperature, humidity) deliver localized values only. It is known that the velocity of ultrasonic waves is affected by changes in the elastic properties, which are again influenced by stress/load state and the degradation mechanisms mentioned above. This is conventionally used in time of flight measurements on lab samples to assess freeze-thaw damage.

New developments allow the design of innovative monitoring systems, which allow the detections of very subtle changes in the structure as well as (at least roughly) delineating the damaged zones. Most promising is a technique called Coda Wave Interferometry (CWI), which is able to detect small velocity changes compared to a reference measurement which an accuracy unknown so far [8]. CWI uses the information of the late part of the ultrasonic signals, containing information from multiple scattering and reflections, independent of wave type and direction, but also from outside the direct path between transmitter and receiver. The use of the technique on concrete has been demonstrated in the lab [e.g. 9, 10,11] and at real sites $[12,13]$. Localization capabilities have been shown in [14] and are currently improved by the German research project MIIC. Two examples are presented below.

The application of CWI for lab investigation can be shown by evaluating the change of ultrasonic velocity due to temperature influence, an effect which has to be accounted for in monitoring applications. A set of three concrete prisms with two embedded ultrasonic sensors (Fig. 6 right) have been put in a climate chamber and subjected to several heating and cooling cycles between 0 and $50{ }^{\circ} \mathrm{C}$ in $4 \mathrm{~K}$ steps.

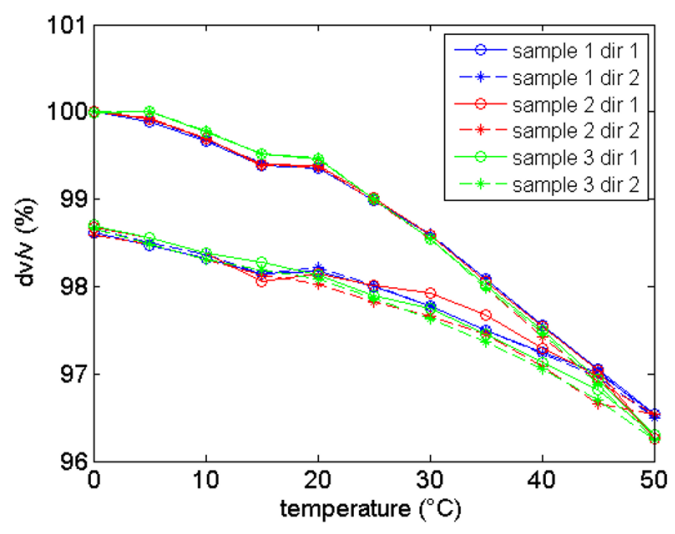

Fig. 9. Ultrasonic velocity variation $\mathrm{dv} / \mathrm{v}$ for first temperature cycle for three different samples, each with two measurement configurations [11].

The result of the evaluation is shown in Fig. 9. The average velocity drop (corrected for thermal expansion, which was hardly measurable) due to temperature was around $0.06 \%$ per $\mathrm{K}$ during the heating cycle. The velocity only partly recovered after cooling, probably due to early age effects, the sample being only 3 months old and still subject to shrinking and subsequent opening of very small cracks. The results show, that subtle changes in the concrete can be monitored with a sensibility (in terms of velocity change) up to $2 * 10^{-5}$. Details of the experiments are described in [11]. 


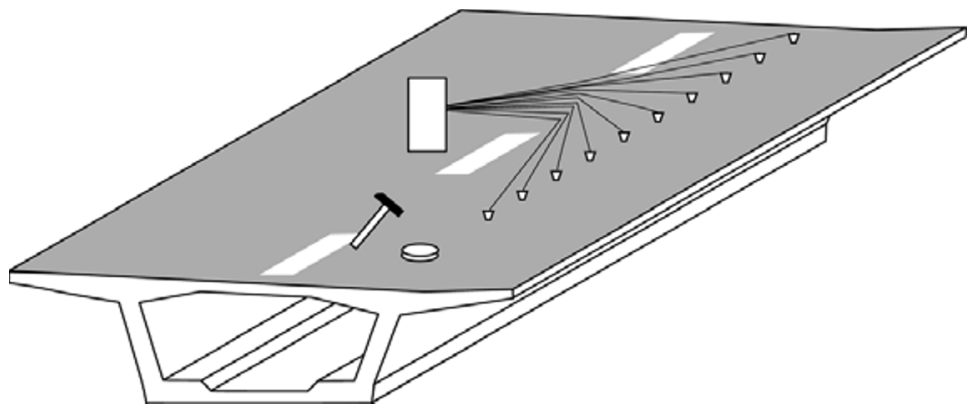

Fig. 10. Sketch of the experimental setup with the hammer source and the geophones [13].

An experiment on a real bridge during construction was carried out by S. Stähler in 2009 [13]. A hammer source and geophones have been used on a prefabricated bridge deck (Fig. 10) which was moved from its construction place to the final location over the pillars. A simulation was carried out to determine the theoretical stress state during the phases of movement and the according changes in sonic velocity. These have been compared to the actual measurements, which have been evaluated by CWI (Fig. 11) and show a reasonable agreement. Lab experiments with direct comparison between load, stress and CWI results are described in $[9,10]$ showing that CWI results can be quantified.

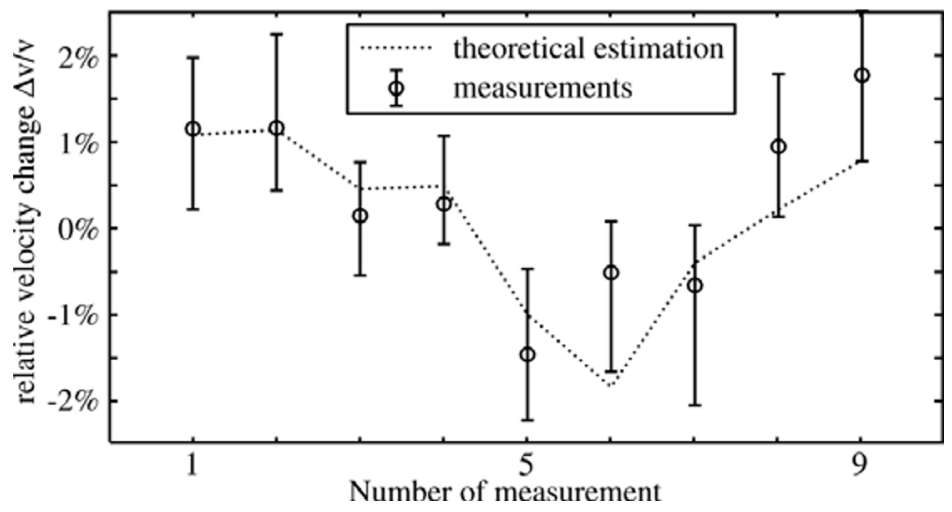

Fig. 11. Measured velocity variations in bridge with quartile limits, compared with results from simulation [13].

\section{Conclusions and outlook}

Ultrasonic techniques to image structures and to monitor changes inside large concrete structures have been improved widely in the last decade. These improvements include sensors and sensor arrangements, array techniques, automated data acquisition as well as various data processing techniques. Some of the new methods may require further research and development. However, a set of tools is available for practical application, which will help in the assessment of aging large concrete structures. 


\section{References}

1. M. Schickert, M. Krause, Ultrasonic techniques for evaluation of reinforced concrete structures, in: Ch. Maierhofer, H.-W. Reinhardt, G. Dobmann (eds.); Non-destructive evaluation of reinforced concrete structures, Woodhead Publishing Limited, Cambride, Part II.22, pp. 490$530(2010)$

2. M. Krause, Localization of grouting faults in post tensioned concrete structures, in: D. Breysse (ed.); Non-Destructive Assessment of Concrete Structures: Reliability and Limits of Single and Combined Techniques. State-of-the-Art Report of the RILEM Technical Committee 207-INR, Springer (2012) Chap. 6, pp. 263-304

3. M. Friese, F. Mielentz, H. Wiggenhauser, Ultraschall-Linienarray zur Untersuchung von Betonbauteilen, in: Tagungsband zur Fachtagung Bauwerksdiagnose (2008), Praktische Anwendungen Zerstörungsfreier Prüfungen und Zukunftsaufgaben, 21.-22.02.2008, Berlin, Berichtsband BB 112-CD, Poster 9

4. M. Krause, B. Milmann, F. Mielentz, D. Streicher, B. Redmer, K. Mayer, K.-J. Langenberg, M. Schickert, Ultrasonic Imaging Methods for Investigation of Post-Tensioned Concrete Structures: A Study of Interfaces at Artificial Grouting Faults and its Verification, Journal of Nondestructive Evaluation 27 (2008) 1-3, pp. 67-82

5. S. Müller, E. Niederleithinger, T. Bohlen, Reverse Time Migration: A Seismic Imaging Technique Applied to Synthetic Ultrasonic Data, International Journal of Geophysics (2012) Article ID 128465, 7 pages

6. A. Taffe, Dickenmessungen von Fundamenten und Ermittlung der Messunsicherheit, in: Bergmeister, K. (Hrsg.) Beton-Kalender 2007, Berlin: Ernst und Sohn (2007), Kap. V, Abschnitt 12

7. R. Snieder, A. Grêt, H. Douma, J. Scales, Coda wave interferometry for estimating nonlinear behavior in seismic velocity, Science, 295 (2002) p. 2253-2255

8. C. Sens-Schönfelder, U. Wegler, Passive image interferometry and seasonal variations of seismic velocities at Merapi Volcano, Indonesia, Geophys. Res. Lett. 33 (2006) p. L21302

9. P. Shokouhi, E. Niederleithinger, A. Zoëga, A. Barner, D. Schöne, Using Ultrasonic Coda Wave Interferometry for Monitoring Stress-Induced Changes in Concrete, in: Proceedings of the EEGS Annual Meeting 23rd SAGEEP, Symposium of the Application of Geophysics to Engineering and Environmental Problems, 11.-15.04.2010, Keystone, CO, USA

10. Y. Zhang, O. Abraham, E. Larose, T. Planes, A. Le Duff, B. Lascoup, V. Tournat, R. El Guerjouma, L.-M. Cottineau, O. Durand, Following stress level modification of real size concrete structure with coda wave interferometry (cwi), in: AIP Conference Proceedings, 1335 (2011) pp. 1291-1298

11. E. Niederleithinger, C. Wunderlich, Influence of small Temperature Variations on the Ultrasonic Velocity in Concrete, in: AIP Conference Proceedings, Review of Progress in QNDE, Vols 31A and 31B, Denver, CO, USA, 15.-20.07.2012, 1511 (2013) pp. 390-397

12. E. Larose, J. de Rosny, L. Margerin, L., D. Anache, P. Gouedard, M. Campillo, B. van Tiggelen, Observation of multiple scattering of $\mathrm{kHz}$ vibrations in a concrete structure and application to monitoring weak changes, Physical Review E 73 (2006) 0166091

13. S. Stähler, C. Sens-Schönfelder, E. Niederleithinger, Monitoring stress changes in a concrete bridge with coda wave interferometry, J. Acoust. Soc. Am., 129 (2011) 4, p. 1945-1952

14. E. Larose, T. Planes, V. Rossetto, L. Margerin, Locating a small change in a multiple scattering environment, Appl. Phys. Lett. 96 (2012) id. 204101 